Research Article

\title{
Mechanical Model of Underground Shaft Coal Pocket and Deformation of Silo Wall in Coal Mines
}

\author{
Yongping Wu, ${ }^{1,2}$ Mingyin Liu $\mathbb{D}^{1,3}$ Wenyu Lv, ${ }^{1,2}$ and Bosheng $\mathrm{Hu}^{1}$ \\ ${ }^{1}$ School of Energy and Resource, Xi'an University of Science and Technology, Beilin District, Xi'an, Shaanxi 710054, China \\ ${ }^{2}$ Key Laboratory of Western Mine Exploitation and Hazard Prevention of the Ministry of Education, Beilin District, Xi'an, \\ Shaanxi 710054, China \\ ${ }^{3}$ Taiyuan Design Research Institute Group Co., Ltd. for Coal Industry, Yingze District, Taiyuan, Shanxi 030001, China
}

Correspondence should be addressed to Mingyin Liu; liumingyin2004@163.com

Received 6 August 2020; Revised 13 September 2020; Accepted 24 September 2020; Published 14 October 2020

Academic Editor: Jianping Zuo

Copyright (c) 2020 Yongping Wu et al. This is an open access article distributed under the Creative Commons Attribution License, which permits unrestricted use, distribution, and reproduction in any medium, provided the original work is properly cited.

\begin{abstract}
In order to provide a theoretical basis for the design of underground shaft coal pocket and support parameters in coal mines, a mechanical model and a dynamic analysis of the silo wall are established based on the engineering background of Ganhe Coal Mine. The numerical calculation is carried out by using the new model. The back analysis of the silo wall damage in the actual project is carried out, and the deformation law and fracture mechanism of the silo wall affected by different lateral pressure coefficients are analyzed and studied research. Based on the Mohr-Coulomb strength criterion, five sets of orthogonal simulation experiments were carried out for lateral pressure coefficients of $0.6,0.8,1.0,1.2$, and 1.4, respectively. The results show that the lateral pressure coefficient is the main factor affecting the deformation of the silo wall, the radial displacement of the silo wall increases gradually with the increase of the lateral pressure coefficient, and the displacement follows the quadratic polynomial function distribution. The maximum tensile stress area of the silo wall is located in the middle and lower part of the shaft coal pocket, which better explains the engineering phenomenon that the actual fracture location of the silo wall is mostly concentrated in the middle and lower part of the underground shaft coal pocket. The targeted repair technology can be used for reference in engineering.
\end{abstract}

\section{Introduction}

The underground shaft coal pocket plays a crucial role in the storage and transportation of coal for the mines, which can balance the transport capacities for both the main shaft and the main haulage roadway. Due to its long service duration, the shaft coal pocket generally serves for a special level as vital and lasting importance, determining the production safety of the whole mine. It is absolutely necessary and even sometimes exhibits the multibunkers for the mode of vertical shaft development, which was also frequently utilized for the inclined shaft development. The silo wall of vertical cylindrical concrete is the most versatile mode for the shaft coal pocket. Practice has indicated that the damage of the shaft coal pocket frequently occurs due to the destruction and instability of the silo wall. Recently, underground shaft coal pocket accidents have occurred occasionally and even caused serious casualties.

For the present underground shaft coal pocket in the mines, the origin silo wall could be damaged of various degrees and some could even be destroyed despite several maintenances with the increase of coal amount and service duration. There exists great significance to investigate the stability of the silo wall under different lateral pressure coefficients. There have been fruitful investigations on the shaft lining, surface silo, and oil drilling engineering to date. However, systematic research on the silo wall of the shaft coal pocket has been minimally reported. Compared with the common underground roadways, the silo wall passes through several anisotropic mediums and frequently contacts with several or even dozens of strata, increasing the complexity of this research. The phenomenon of unloading 
overpressure in shaft coal pocket has been proved, which can be revealed by the mechanical behaviors under different lateral pressure coefficients. Thus, it is critical for the reasonable determination of the mechanical model of the silo wall and the investigation of the stability for the silo wall under different lateral pressure ratios.

Through the two-dimensional stress distribution solution around the circular pores in the elastic plate, $\mathrm{Ma}$ proposed that the coefficient of lateral pressure is a direct reflection of the stress environment of the surrounding rock [1]. Zhu et al. explored the relationship between the well deformation of the underground chamber and the load and considered that the sidewall displacement can be affected by conditions such as being deeply buried, poor rock quality, and high lateral pressure coefficient [2]. Jia analyzed the stress and elastic properties of the surrounding rocks for a circular roadway with two-way equal pressure [3]. Xu [4] and $\mathrm{Xu}$ [5] have conducted an analysis of the elastic-plastic basic theory of thick-walled cylinders. The Chinese standard concerning coal mine silo has classified the side pressure coefficients of deep bin as 0.9-1.4 [6]. Both Fan and Zheng [7] and Yuan [8] calculated the side pressure of the silo wall via the finite element method and concluded that the maximum horizontal pressure is 1.42 times the minimum value. Liu and $\mathrm{Wu}$ [9] have investigated the repair design of the underground shaft coal pocket engineering process. Chen [10] considered that the unloading form has a great influence on the lateral pressure of silo. Wang and Yang [11] conducted the wellbore stress analysis for the lateral pressure coefficient of $0-1$. Xiong et al. [12] investigated the uniform pressure distribution in the silo. Shao et al. [13] analyzed the coal unloading technology of coal bunker given the lateral pressure coefficient of 1.0. Li et al. [14] experimentally investigated the stability of the concrete arch under different lateral pressure coefficients. Sun et al. [15] derive four wall pressure coefficients in quasiplane strain to consider the intermediate stress effect under four criteria. Tatkoa and Kobielak [16] carry out the laboratory tests in the steel flatbottomed silo model filled with sand. Kong et al. [17] carry out the triaxial compression tests under different confining pressures and loading methods to investigate the deformation characteristics of the coal specimens. Wang et al. [18] study the large-deformation failure mechanism of coal feeder chamber and construction of wall-mounted coal bunker. Yan et al. [19], on the basis of the engineering background of Nantun Coal Mine, studied the shaft deformation and failure characteristics. All these have provided preliminary research proposals for the stress analysis of the bunker wall at the shaft coal pocket.

Here, the mechanical model of the shaft lining was constructed concerning the underground shaft coal pocket of Ganhe mine. Five series of orthogonal numerical simulation experiments were conducted considering different side pressure coefficients to analyze the stress-strain properties and distribution of the ductile zone following the Mohr-Coulomb strength criterion. Finally, the deformation law and damage mechanism were investigated, which provide the theoretical basis for engineering practice and foundation for the later investigation on the stability of the coal bunker wall.

\section{Background}

The Ganhe Coal Mine is located in the north of Huozhou mining area in Huoxi coalfield, Shanxi Province, and its administrative division is under the jurisdiction of Hongtong County, Linfen City. The shape of the minefield is NESW long strip distribution. The length of NE-SW is about $9 \mathrm{~km}$, and the width of NW-SE is about $4 \mathrm{~km}$, with an area of $35.559 \mathrm{~km}^{2}$.

Ganhe Coal Mine shaft coal pocket is the only one in this mine. It is located at $24.5 \mathrm{~m}$ West by north of the main shaft, with a net diameter of $\Phi 7 \mathrm{~m}$ and a height of $47.39 \mathrm{~m}$. The level of the upper coal bunker opening is $+79.8 \mathrm{~m}$ and the Earth's surface level is $+546.4 \mathrm{~m}$. The silo wall is made of C20 plain concrete arch with a supporting thickness of $450 \mathrm{~mm}$ and a capacity of $1700 \mathrm{~m}^{3}$, which is a high-capacity shaft coal pocket. The construction of the shaft coal pocket began in December 2007 and was completed in February 2008. The bunker body was damaged for the first time in 2011, then collapsed gradually, and became serious from the end of 2015 to April 2016. According to the observations on May 25,2016 , and June 2, 2016, the damaged section is located at the level of $+44.8 \mathrm{~m}$ to $+62.8 \mathrm{~m}$, with the maximum collapsed areas depth of $5 \mathrm{~m}$ and height of 7-8 $\mathrm{m}$. The damage and collapse direction are mainly in the south side and some extend to the east and west sides of the shaft coal pocket. The serious collapse area accounts for two-thirds of the section perimeter, and the surrounding rock collapsed areas volume reaches about $1000 \mathrm{~m}^{3}$.

\section{Mechanical Model}

Based on the actual engineering practice of Ganhe mine, the rock mechanical model can be constructed as Figures 1(a) and 1(b). The size and end effect of the coal bunker upper end was ignored to highlight the stress state of the silo wall. The overlying strata which are not simulated here are simplified as uniformly distributed loads applied on the upper boundary of the model. Additionally, there exist unconformity contacts between the silo wall and surrounding rocks due to the excavation of rocks and concrete arch support. This can be classified into three cases: (1) perfect contact, (2) hinged contact between upper and lower ends, and (3) partial contact between silo wall and surrounding rocks, where case 2 was the most unfavorable and prone to deformation and damage. The simplified mechanics 


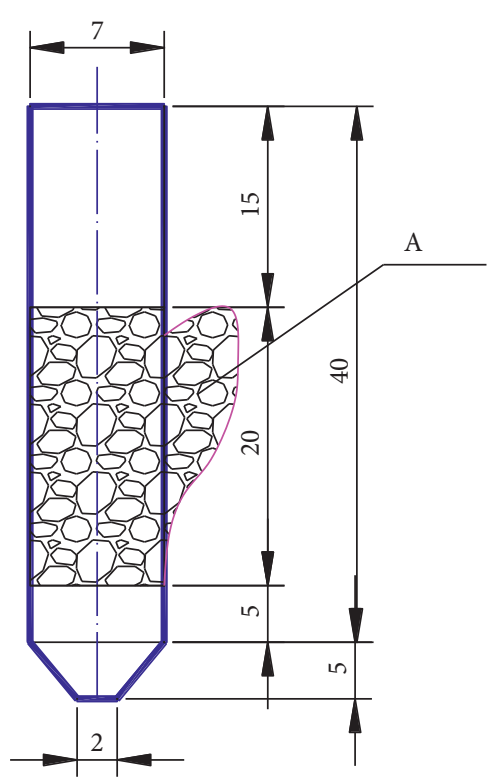

(a)

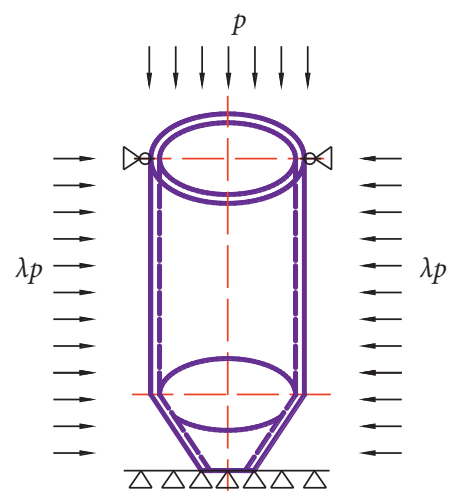

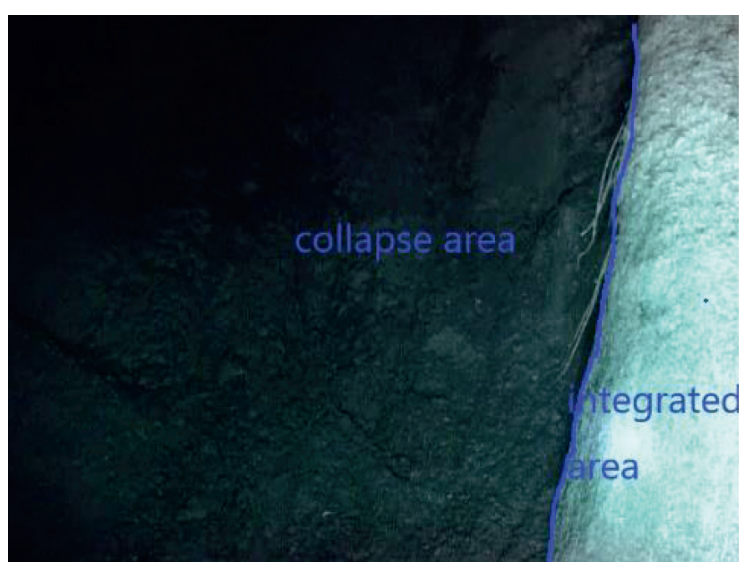

(b)

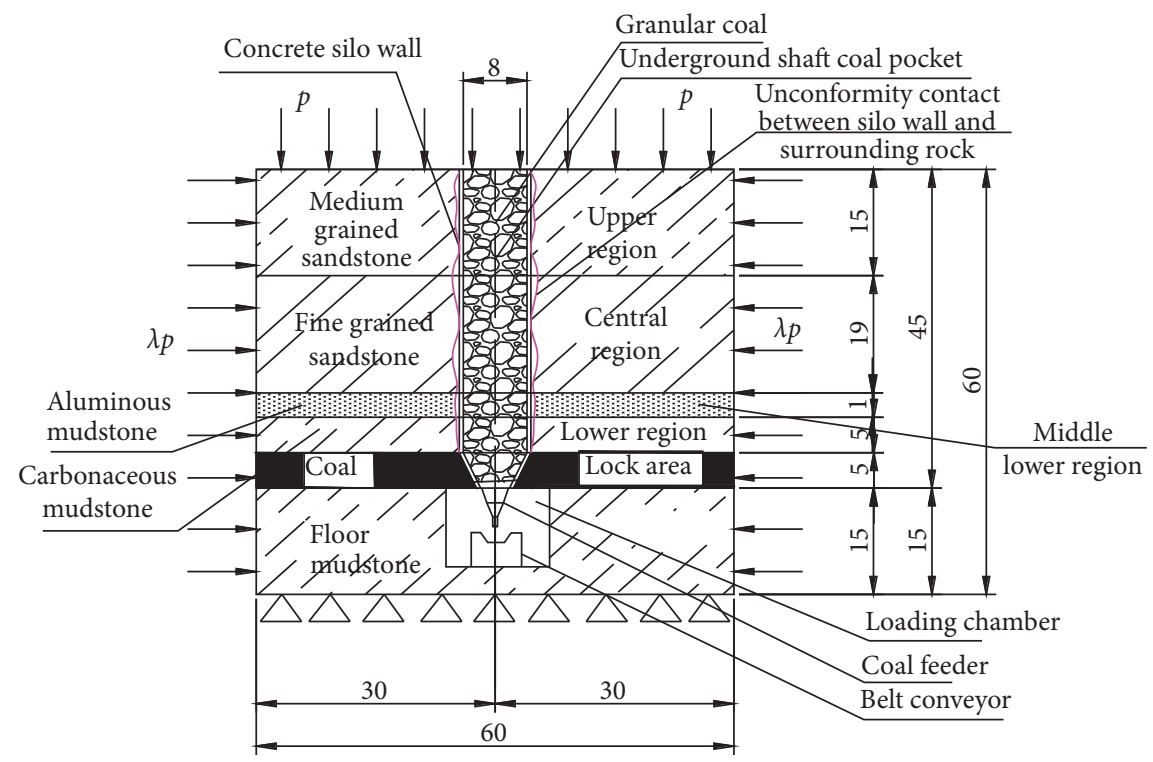

(d)

(c) FIGURE 1: Simplified mechanical model of concrete shaft wall and surrounding rocks. (a) Damage site of the silo wall where "A" is the
collapse area. (b) Comparison of the collapse area and integrated area [9]. (c) Simplified mechanics model of the silo wall. (d) Simplified mechanics model of the silo wall and surrounding rocks.

model of the silo wall and inclusion of the surrounding rocks are depicted in Figures 1(c) and 1(d), respectively.

As the height of bulk coal is constantly changing in the actual mine production process, the two limit static conditions were preferentially considered: A, empty position status, and B, full-position status. Then, the dynamic working processes between these two conditions were considered, that is, the coal loading process I (dynamic behaviors from condition A to condition B) and coal unloading process (dynamic behaviors from condition $\mathrm{B}$ to condition A). Based on the novel established model, the mechanical analysis is conducted via the theoretical research and numerical experiment.

\section{Mechanical Analysis of Silo Wall}

\subsection{Elastic-Plastic Mechanical Analysis of Silo Wall}

4.1.1. Stress Components. Actually, the wall of the coal bunker at the underground coal mine is buried in layered strata; however, for the wall in a specific rock stratum, when at the full-position status, it can be equivalent to the mechanical model of cylinder bearing internal pressure in the infinite elastic body [4]. The stress distribution of the cylinder wall with bearing uniform pressure $q_{a}$ is depicted in Figure 2(a). The equivalent diagram of the internal and external pressure model is depicted in Figure 2(b) when 


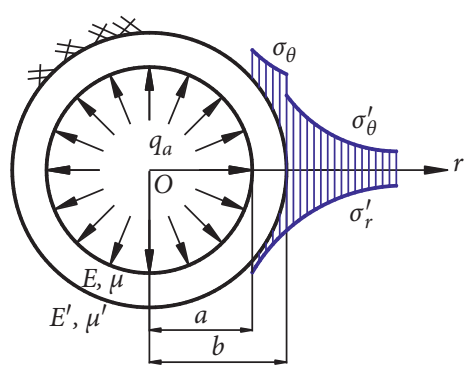

(a)

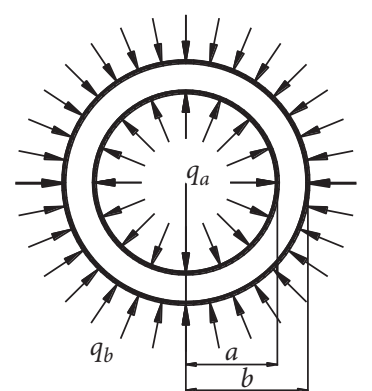

(b)

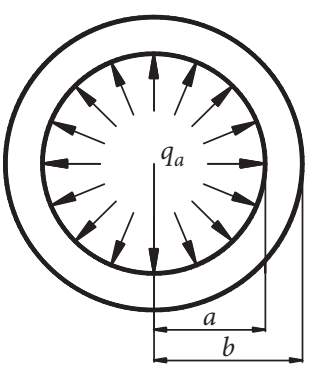

(c)

FIgURE 2: Stress distribution of the shaft wall. (a) Stress distribution of the silo wall mechanical model. (b) Equivalent diagram of internal and external pressure model on the silo wall. (c) Equivalent diagram of the internal pressure model on the silo wall.

there exists a bulk coal medium inside the silo wall. Figure 2(c) depicted the internal pressure model for the case when there is an unconformity contact outside and loose coal medium inside the coal bunker wall.

The stress component of the silo wall can be expressed as

$$
\begin{gathered}
\sigma_{r}=-q_{a} \frac{[1+(1-2 \mu) n]\left(b^{2} / r^{2}\right)-(1-n)}{[1+(1-2 \mu) n]\left(b^{2} / a^{2}\right)-(1-n)}, \\
\sigma_{\theta}=q_{a} \frac{[1+(1-2 \mu) n]\left(b^{2} / r^{2}\right)-(1-n)}{[1+(1-2 \mu) n]\left(b^{2} / a^{2}\right)-(1-n)}, \\
\sigma_{r}^{\prime}=-\sigma_{\theta}^{\prime}=-q_{a} \frac{2(1-\mu) n\left(b^{2} / r^{2}\right)}{[1+(1-2 \mu) n]\left(b^{2} / a^{2}\right)-(1-n)},
\end{gathered}
$$

where

$$
n=\frac{E^{\prime}(1+\mu)}{E\left(1+\mu^{\prime}\right)}
$$

$\sigma_{r}$-radial principal stress of concrete silo wall, $\mathrm{Pa}$; $\sigma_{\theta}$-circumferential principal stress of concrete silo wall, $\mathrm{Pa}$; $\sigma_{r^{\prime}}$-radial principal stress of surrounding rocks, $\mathrm{Pa}$; $\sigma_{\theta^{\prime}}$-circumferential principal stress of surrounding rock, $\mathrm{Pa}$; E-elastic modulus of concrete silo wall, $\mathrm{Pa} ; E^{\prime}$ - elastic modulus of surrounding rock, $\mathrm{Pa} ; \mu$-Poisson's ratio of surrounding rock; $\mu^{\prime}$-Poisson's ratio of concrete silo wall; $q_{a}$-internal pressure of coal bulk on silo wall, N/m; and $q_{a}=0$ corresponds to empty position status (Condition A).

4.1.2. Elastic Displacement Function of Silo Wall. Based on the thick-walled cylinder theory in elasticity mechanics, the displacement function $u$ of silo wall when enduring the medial pressure $q_{a}$ and lateral $q_{b}$ can be expressed as [4]

$$
\begin{aligned}
u & =\frac{1}{E}\left[(1+\mu) \frac{a^{2} b^{2}\left(q_{b}-q_{a}\right)}{\left(b^{2}-a^{2}\right) r}+(1-\mu) \frac{q_{a} a^{2}-q_{b} b^{2}}{b^{2}-a^{2}}\right], \\
q_{b} & =\lambda p .
\end{aligned}
$$

(1) From Figure 2(b), when $q_{a}=0$, the radial displacement component of the silo wall derived from $q_{b}$ was

$$
u_{b}=\frac{b^{2} q_{b}}{E\left(b^{2}-a^{2}\right)}\left[\frac{(1+\mu) a^{2}}{r}+(1-\mu) r\right] \text {. }
$$

(2) From Figure 2(b), when $q_{b}=0$, the radial displacement component of the silo wall derived from $q_{a}$ was

$$
u_{a}=\frac{a^{2} q_{a}}{E\left(b^{2}-a^{2}\right)}\left[\frac{(1+\mu) b^{2}}{r}+(1-\mu) r\right] \text {. }
$$

\subsubsection{Plastic Stress Component of Silo Wall}

(1) Plastic limit pressure and stress components

For the cylindrical concrete silo wall, when the stress $P$ on the upper boundary of the pressure model increases, the plastic zone expands and the elastic zone shrinks. Due to the limitation of the external elastic zone, the deformation of the internal plastic zone can only be the same order of magnitude as the elastic deformation. When the plastic zone extends to the whole cylinder wall, the plastic deformation will occur without restraint, and the silo wall cannot continue to bear the inner pressure, which is called the plastic limit state. If the pressure of the plastic limit state is $p_{l}$, and $r_{s}=b$, then the plastic limit stress and stress components were [5]

$$
\begin{aligned}
p_{l} & =\sigma_{s} \ln \frac{b}{a}, \\
\sigma_{r}^{\prime} & =\sigma_{s} \ln \frac{r}{a}, \\
\sigma_{\theta}^{\prime} & =\sigma_{s}\left(1+\ln \frac{r}{b}\right),
\end{aligned}
$$

where $\sigma_{s}$ is the plastic limit pressure.

(2) The stress distribution of the silo wall and surrounding rock in the plastic section is given as [6] 


$$
\left(\sigma_{v}\right)_{z}=\frac{11 \gamma_{e} g r}{\lambda k_{0}}\left(1-e^{-\left(\lambda k_{0} / 11 r\right)}\right) .
$$
is

The distribution of the horizontal ground pressure stress

$$
\left(\sigma_{h}\right)_{z}=\lambda\left(\sigma_{v}\right)_{z}=\frac{11 \gamma_{e} g r}{k_{0}}\left(1-e^{-\left(\lambda k_{0} / 11 r\right)}\right),
$$

where $k_{0}$ is the maximum static friction coefficient between the surrounding rock and silo wall and $\lambda$ is the lateral pressure coefficient.

4.2. Coal Loading Process. The variations of the dynamic parameters of coal flow from Condition A to Condition B are as follows:

(1) The height of bulk coal increases from 0 to $H$ of Condition B. $Q_{1}$ and $V$ depicted the coal capacity on the upper belt conveyor and bunker volume, respectively. Then, the theoretical time to fill the coal bunker is $V / Q_{1}$, where $Q_{1}$ is the upper belt freight volume, $\mathrm{t} / \mathrm{s} ; V$ is the capacity of the shaft coal pocket, $t$; and $H$ is the coal height in the shaft coal pocket, $m$.

(2) The velocity of coal flow can be equivalent to free falling motion. The final velocity of falling coal flow is high for Condition A and low for Condition B. The velocity $v_{\max }$ was gradually reduced to the initial speed of the upper belt conveyor $v_{0}$ which is determined by the running speed of the belt conveyor in the upper main transport roadway $\left(v_{\max }=\sqrt{2 g H}\right)$.

4.3. Coal Unloading Process. The variations of the dynamic parameters of coal flow from Condition B to Condition A are opposite to the above.

(1) The height of bulk coal increases from $H$ to $0 . Q_{2}$ and $V$ depicted the coal capacity on the lower coal feeder and coal bunker volume, respectively. Then, the theoretical time to fill the coal bunker is $V / Q_{2}$, where $Q_{2}$ is the capacity lower coal feeder, $t / s$.

(2) For this case, the movement state of coal flow is the most complex. It is not only related to the physical properties of granular particles but also related to the flow state (tubular flow, overall flow, or "turbulent flow") and additionally depends on the scale utility and geometry of the lower discharge port as well, especially for the ratio of the height to radius $k=H$ / $D$. Also, the granular mechanical structure, such as arching and bonding can be formed during the coal loading process, resulting in the blocking accident. The coal loading velocity can be obtained via numerical simulation and filed measurement. However, the field initial coal loading also increased from 0 to the rated speed of coal feeder control plus the additional velocity due to the free fall from the lower port to the height of the belt surface of the belt conveyor. Finally, the stability of the belt conveyor in the transportation system can be ensured, and thus the coal flow velocity of the coal unloading process can be simplified from 0 to $v_{1}$, which is determined by the flow speed of the lower coal feeder.

\section{Numerical Simulation Experiment}

5.1. In Situ Rock Stress. The actual engineering site of the numerical experiment simulation was in Huozhou mine of the Huoxi coalfield, Shanxi Province. The distribution of the in situ rock stress can be referred to in [3]. The maximum horizontal stress is 1.36 times higher than the vertical stress which equals the overburden thickness multiplied by unit weight [20]. The buried depth of this area is $466.6 \mathrm{~m}$, equivalent to the horizontal pressure of $11.7 \mathrm{MPa}$ applied on the upper of the experimental model.

5.2. Yield Criterion. FLAC ${ }^{3 \mathrm{D}}$, the general numerical simulation software of rock concrete material, was adopted here, following the Mohr-Coulomb yield criterion to judge the failure of the rock mass. The criterion is

$$
f_{s}=\sigma_{1}-\sigma_{3} N_{\varphi}+2 c \sqrt{N_{\varphi}}=0,
$$

where

$$
N_{\varphi}=\frac{1+\sin \varphi}{1-\sin \varphi},
$$

where $c$ is the cohesive force $(\mathrm{Pa})$ and $\varphi$ is the internal friction angle of the rock mass $\left({ }^{\circ}\right)$.

5.3. Numerical Modeling. Based on the actual layered surrounding rock stratum of Ganhe Coal Mine, the 3D numerical model is established by FLAC3D using the following boundary conditions. In this paper, the 0 displacement constraint was used in both the vertical direction of the lower boundary and horizontal direction of the upper boundary. Additionally, the stress boundary condition was utilized in the vertical direction of the upper boundary, the horizontal direction of the left and right boundary, and the horizontal direction of the front and rear boundary.

The basic structure unit of the silo wall model was generated via the Generate order, where the inner diameter, thickness, and height were $7.0 \mathrm{~m}, 0.5 \mathrm{~m}$, and $45 \mathrm{~m}$, respectively. The bin is filled with loose coal particles. The rock strata and wall were simulated via the RADCYL and CSHELL unit respectively, generating the 8640 units and 8878 nodes.

The numerical model constructed via the mine geological conditions is depicted in Figures 3(a) and 3(b).

5.4. Designed Normal Test. The lateral pressure of the silo wall varied due to the varying coal loading depth. The lateral pressure coefficients of $0.6,0.8,1.0,1.2$, and 1.4 were selected to conduct the orthogonal experiment here based on the actual in situ stress distribution in Huozhou mining. The mechanics response of the silo wall was simulated concerning the coal unloading process of the underground coal 


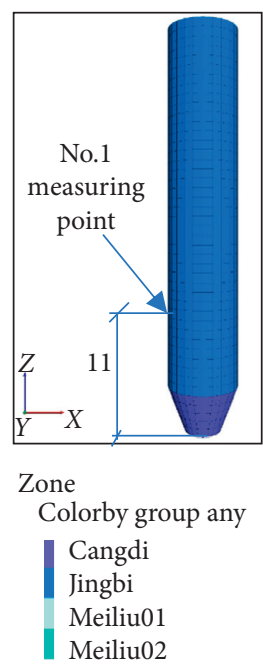

(a)

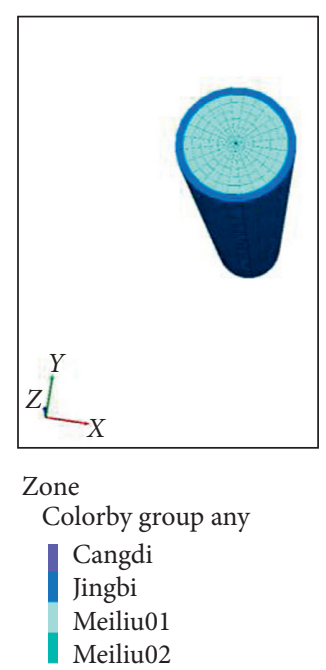

(b)

FIGURE 3: Numerical model of the shaft wall.

TABLe 1: Physical and mechanical parameters of rock mass used in numerical simulation.

\begin{tabular}{|c|c|c|c|c|c|c|}
\hline Rock type & $\begin{array}{c}\text { Density } \\
\left(\mathrm{kg} \cdot \mathrm{m}^{-3}\right)\end{array}$ & $\begin{array}{c}\text { Internal friction angle } \\
\left({ }^{\circ}\right)\end{array}$ & $\begin{array}{c}\text { Tensile strength } \\
(\mathrm{MPa})\end{array}$ & $\begin{array}{c}\text { Elastic modulus } \\
(\mathrm{GPa})\end{array}$ & $\begin{array}{c}\text { Cohesion } \\
(\mathrm{MPa})\end{array}$ & $\begin{array}{l}\text { Poisson } \\
\text { ratio }\end{array}$ \\
\hline Coal & 1430 & 39.5 & 0.2 & 0.10 & 0.42 & 0.32 \\
\hline $\begin{array}{l}\text { Concrete silo wall } \\
\text { C30 }\end{array}$ & 2385 & 54.9 & 1.0 & 30 & 3.18 & 0.2 \\
\hline
\end{tabular}

bunker. The distribution characteristics of stress and the strain and plastic zone were also analyzed and determined under various supporting types.

In the coal bunker, the bulk coal was filled first; then the coal body is excavated to simulate the coal unloading process, analyzing the radial displacement and deformation characteristics of the silo wall under different lateral pressure coefficients.

5.5. Determination of Experimental Parameters. The concrete strength grade was C30 in this engineering. The elastic modulus, compressive strength, and tensile strength were $30 \mathrm{GPa}, 20.1 \mathrm{MPa}$, and 2.01 MPa, respectively, following the Chinese standard concrete structure design code (GB 500102010) [21]. The plain concrete support was utilized to investigate the inversion of silo wall deformation based on the actual mine engineering.

According to the mechanical parameters of previous experiments, the physical and mechanical properties of rock masses in the simulation experiment are shown in Table 1 after considering a certain strength reduction factor.

\section{Deformation Analysis of Silo Wall}

The working process of the underground coal bunker was actually the loading or unloading of coal for the silo wall. And the stress environment of the silo wall and surrounding rock continually changes, resulting in the deformation of the silo wall under the inner lateral pressure.
6.1. Stress Analysis. Numerical analysis is conducted at the maximum lateral pressure coefficient of 1.4 under the most unfavorable case of wall stress. Figure 4 depicted the stress nephogram of the vertical section in the stress field on the silo wall. Figure 4 depicted the stress distribution of the vertical profile. It could be concluded that the vertical stress distribution is highly inhomogeneous. There are obvious stress concentration areas in the middle and lower parts of the silo wall, and this is also the area where the maximum tensile stress of the silo wall is generated. As the concrete of the silo wall belongs to the brittle materials, the allowable tensile strength is much lower than the allowable compressive strength, resulting in the preferable damage site in the area of maximum tensile stress. The silo wall will generate fractures under the tensile stress until failure. This is the cause of the actual phenomenon that the damage frequently occurs in the middle and lower part of the silo wall. According to the lithology analysis of the wall rock, the surrounding rocks of this area are composed of the weakest aluminous mudstone.

The stress distribution for other $\lambda$ values was similar to Figure 4 despite their lower stress values. From Figure 4, we can found that the maximum pressure is $44.7 \mathrm{MPa}$, which occurred in a lower area of the shaft coal pocket. Thus, the following will emphatically analyze the displacement properties.

6.2. Deformation Analysis. Like other concrete structures, the deformation of the concrete shaft coal pocket wall chiefly consists of stress deformation and volume deformation. The 


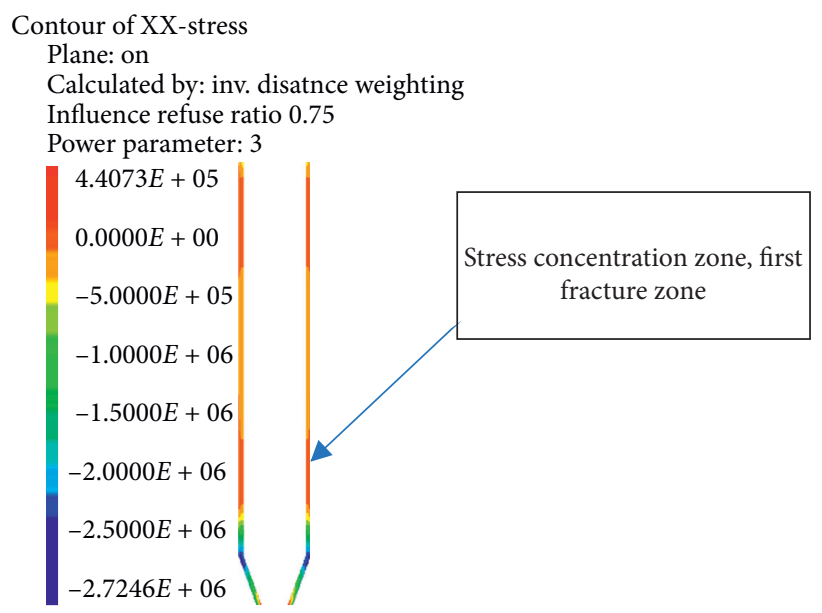

FIgURE 4: Cloud chart of stress distribution in the vertical section of the shaft wall (unit: MPa).

former mainly refers to the deformation caused by one short-term loading, long-term loading, or multiple repeated cyclic loading, while the latter refers to the deformation caused by the concrete itself when it hardens and shrinks or the ambient temperature changes. This research mainly focuses on the deformation under stress.

According to the experimental results of numerical simulation, number 1 measuring point was selected for typical analysis of its radial displacement at $11 \mathrm{~m}$ from the lower end of the shaft coal pocket, the deformation of the shaft wall, and the radial displacement data table of measuring point 1 as Table 2 .

According to the experimental results of numerical simulation, number 2 measuring point was selected for typical analysis, including its horizontal displacement at $23.5 \mathrm{~m}$ from the lower end of the shaft coal pocket, the deformation of the shaft wall, the displacement nephogram under diverse lateral pressure coefficients, and so forth, as shown in Figure 5. Figures 5(a)-5(e) show the horizontal displacement nephograms when the coefficients of lateral pressure $(\lambda)$ are $0.6,0.8,1.0,1.2$, and 1.4, respectively, at the same elevation (the position shown in the figure is $Z=23.5 \mathrm{~m}$ and the bottom end of the shaft is set to $Z=0.0$ ). Meanwhile, the radial displacement along the horizontal section of the shaft wall presents nonlinear increase with the rise of the lateral pressure coefficient. The circumferential displacement nephogram in the stress field on the shaft wall indicates that the distribution of circumferential deformation is extremely uneven. The shaft wall is displaced by hoop tension and then develops into fractures until damaged.

Figure 6 is a dynamic diagram of the radial displacement of number 1 measuring point on the shaft wall arranged $11 \mathrm{~m}$ from the bottom of the shaft coal pocket when the coefficients of lateral pressure are $0.6,0.8,1.0,1.2$, and 1.4, respectively.

As shown in Figure 6, the radial displacement of number 1 measuring point enlarges simultaneously when the coefficient of lateral pressure $(\lambda)$ gradually grows and the other factors remain unchanged, and the displacement of the measuring point tends to reach a stable value when the
TABLE 2: Results of shaft coal pocket wall displacement test (measuring point 1 ).

\begin{tabular}{lccccc}
\hline Lateral pressure coefficient & 0.6 & 0.8 & 1.0 & 1.2 & 1.4 \\
\hline Radial displacement $(\mathrm{mm})$ & -28 & -45 & -55 & -73 & -141 \\
\hline
\end{tabular}

number of cycles reaches around 20,000 times. While $\lambda$ increases from 0.6 to 1.4 , the radial displacement of number 1 measuring point gradually increases from $0.28 \mathrm{~mm}$ to $1.47 \mathrm{~mm}$ and the coefficient of lateral pressure increases by 2.3 times; however, its displacement value basically increases by 5 times. In the meantime, the growth rates of radial displacement are $60.7 \%, 22.2 \%, 23.6 \%$, and $79.4 \%$, respectively. On the whole, the growth rate of radial displacement basically decreases first and then increases.

Figure 7 displays the displacement curve of the shaft wall at number 1 measuring point under diverse lateral pressure coefficients.

Figure 7 shows that the slope of the curve increases significantly when the coefficient of lateral pressure exceeds 1 , indicating that the increasing range of the radial displacement $(\lambda>1)$ is obviously greater than the stage when $\lambda$ is less than 1. In addition, the displacement of the silo wall enlarges distinctly at this critical point, which can easily result in structure deterioration and instability of the silo wall.

According to the experimental results of numerical simulation, the maximum radial displacement of the silo wall during coal unloading is $14.1 \mathrm{~mm}$ and located in the middle and lower areas of the shaft coal pocket, which isconsistent with the actual records of on-site observation.

By analyzing the radial displacement curve of the shaft wall, the fitting curve can be obtained as shown in Figure 8. Number 1 measuring point is set at a radial distance of $0.3 \mathrm{~m}$ from the inner shaft wall and $11 \mathrm{~m}$ from the bottom part of the shaft wall. As shown in Figure 8, the quadratic polynomial curve of this measuring point is fitted and the $R^{2}$ value is 0.9562 . The radial displacement of other measuring points set along the axial direction under different lateral pressure coefficients has indicated a similar rule 


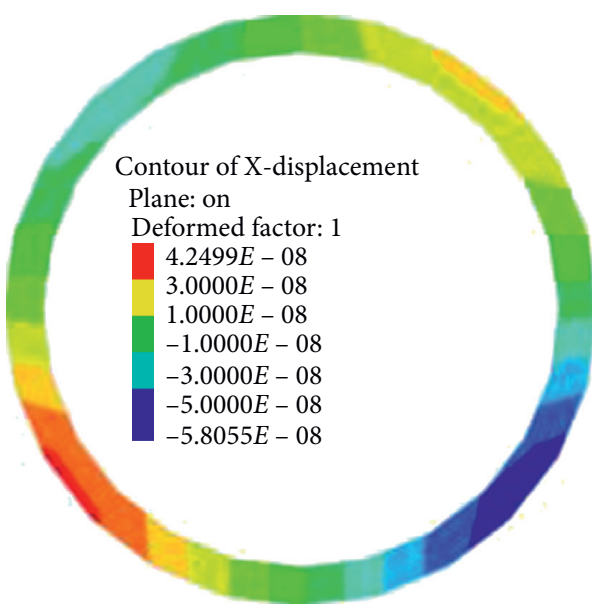

(a)

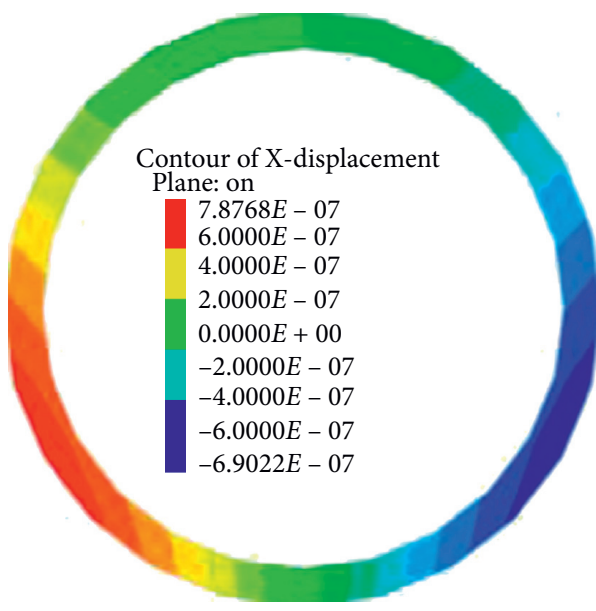

(c)

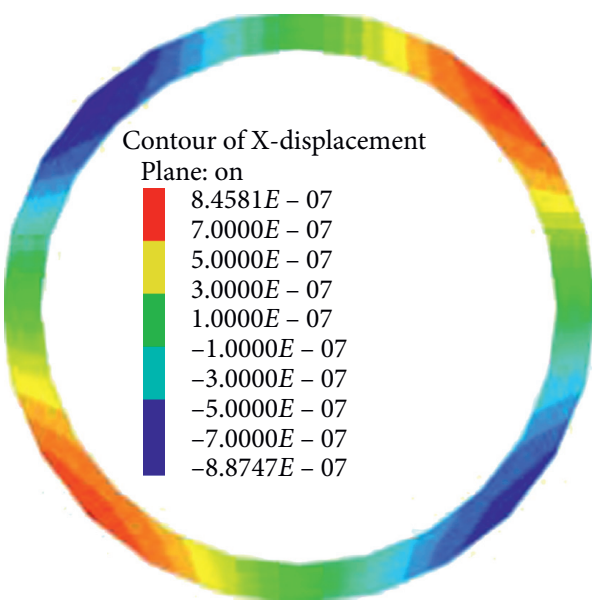

(b)

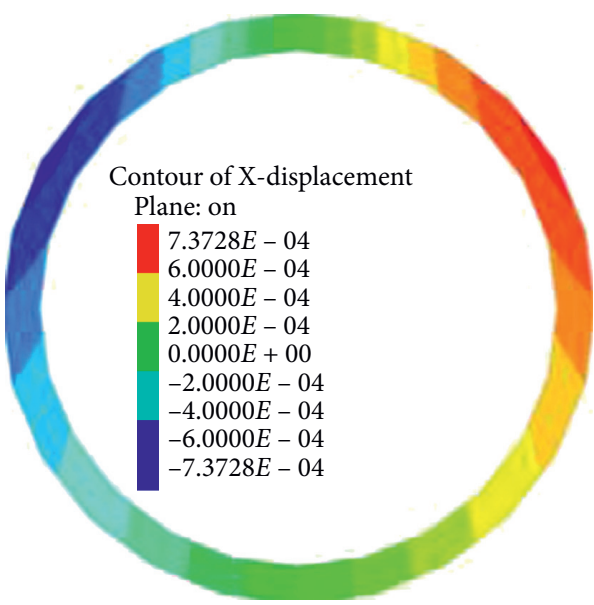

(d)

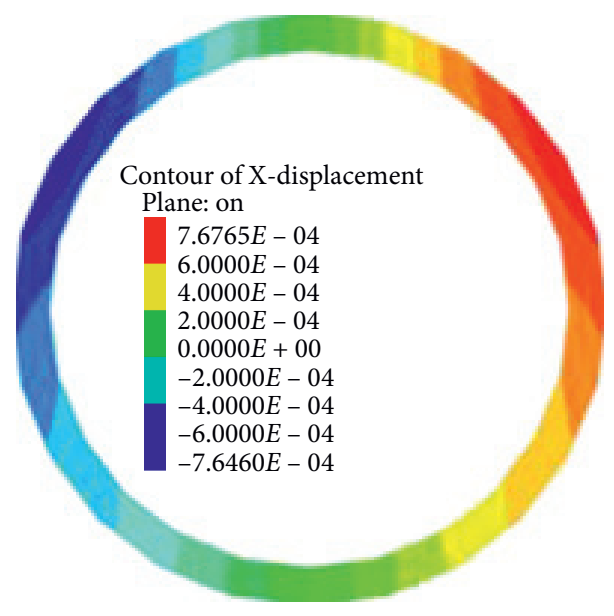

(e)

Figure 5: Cloud chart of radial distribution along displacement horizontal section, $z=23.5 \mathrm{~m}$ from the bottom (unit: $\mathrm{m}$ ). (a) $\lambda=0.6$. (b) $\lambda=0.8$. (c) $\lambda=1.0$. (d) $\lambda=1.2$. (e) $\lambda=1.4$.

to that of number 1 measuring point, which will not be repeated here.

Through analyzing the displacement of the shaft wall and its surrounding rock masses, it has been found that the radial displacement of some areas with the surrounding rock made up of aluminum and carbonaceous mudstone is significantly larger than that of other rock layers under the same lateral pressure. In the meantime, these areas tend to be damaged at first due to the poor mechanical properties of rock strata, so they are key to dominating the entire support system. When 


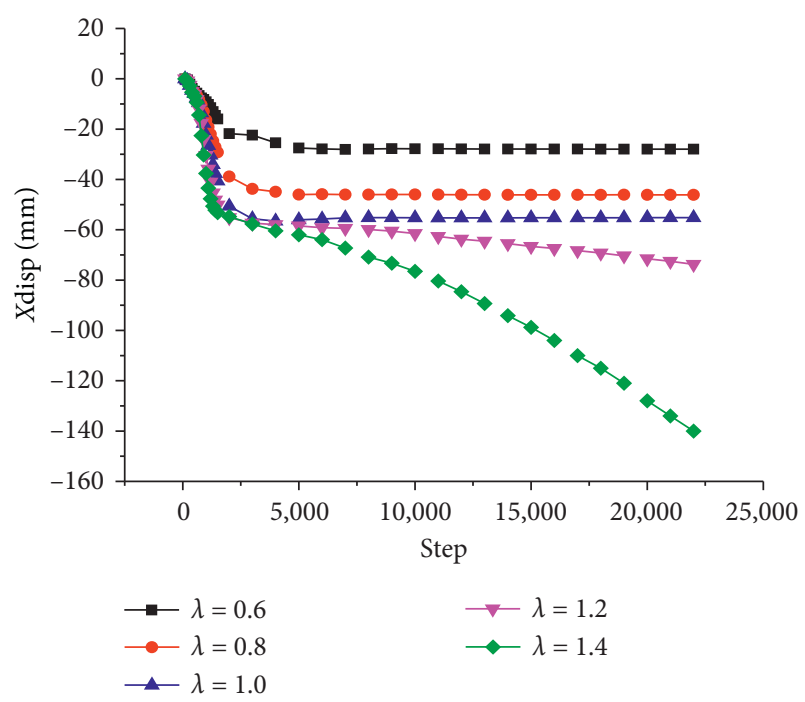

FIGURE 6: Dynamic diagram of the radial position of number 1 measuring point in the middle of the shaft wall $(z=11 \mathrm{~m}$ from the bottom).

the fracture develops to a certain degree, the concrete material on the shaft wall will peel off and drop inside the shaft coal pocket. Then, the peeling phenomenon further expands under repeated loading and unloading actions on the silo wall and larger holes are formed in the working process of the shaft coal pocket. Eventually, the shaft wall gets damaged and the surrounding rock collapses, forming a situation where the shaft wall reaches a depth of several meters like Ganhe Coal Mine and the collapse depth exceeds the radius of the coal bunker and endangering the normal production of the entire main transportation system as well as the mine.

6.3. Analysis of the Plastic Zone. The structure of the concrete shaft wall is also made of multiphase composite material composed of coarse aggregate and hardened cement slurry. There exist original pores and microcracks. The structural damage is a process of gradual changes. In the following part, the distribution scope of the plastic zone is employed as an indicator to determine the instability process of the silo wall.

According to the results of numerical experiments, the distribution of the plastic zone of the silo wall under different $\lambda$ values is shown in Figures 9(a)-9(e). The analysis shows that the vertical plastic zone along the silo wall expands and becomes increasingly uneven when the lateral pressure coefficient grows. When $\lambda$ reaches a certain value, plastic failure first occurs in the middle and lower areas of the silo wall and then gradually expands. In the later period, shear failure appears in the lower and middle areas of the silo wall.

Figure 9 also suggests that the plastic zone on the silo wall is mainly concentrated in the middle and lower areas and gradually expands from bottom to top as the lateral pressure coefficient increases. This is mainly due to the

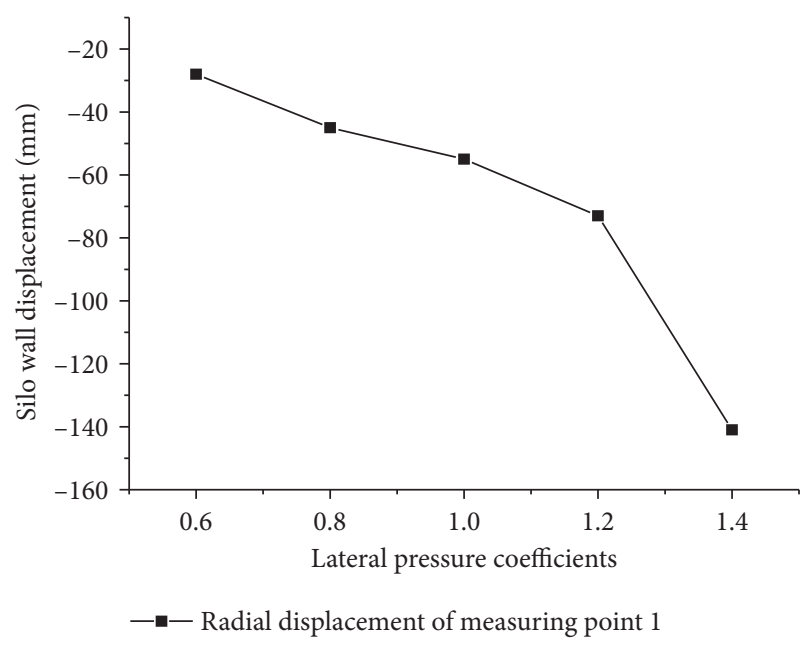

FIGURE 7: Radial displacement curve of number measuring point in the middle of the shaft wall.

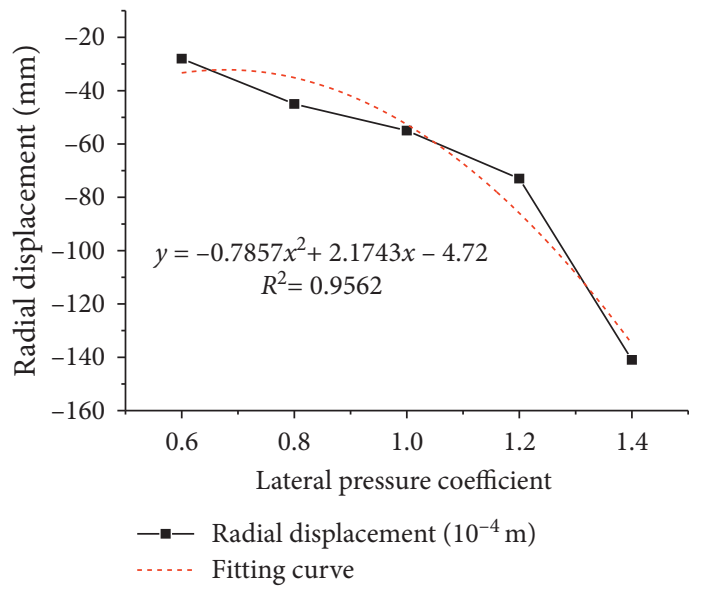

FIgURE 8: Radial displacement fitting curve of number 1 measuring point.

complex flow pattern of loose coal particles during the coal unloading process in this area, which causes the change of the stress state on the silo wall in this area and results in stress concentration. Nevertheless, as the middle part of the silo wall is mostly in the state of tubular flow, the plastic zone in this area is small. Under the action of the internal dynamic pressure, the actual difference between the inner and outer pressure of the silo wall is at its maximum in this area due to the pressure imbalance between the inside and outside of the silo wall, which is conducive to the formation of the plastic zone. As time goes by, the plastic zone will firstly fracture and turn unstable under the action of long-term nonlinear cyclic loading in this area, and the expansion of failure regions may lead to the instability and damage of the integrated system if not restored timely. According to the results of numerical experiments and through numerical simulation experiments analysis, the numbers of plastic zone elements are 2326, 2868, 2959, 4096, and 4291 under five different lateral pressure coefficients, and the total numbers of elements in the shaft coal pocket wall model are 8640 . The 


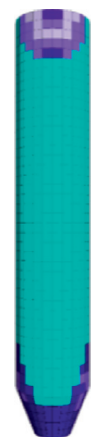

(a)

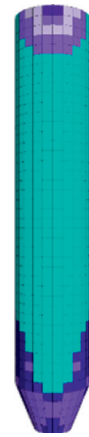

(b)

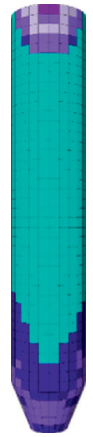

(c)

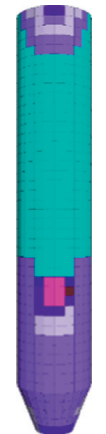

(d)

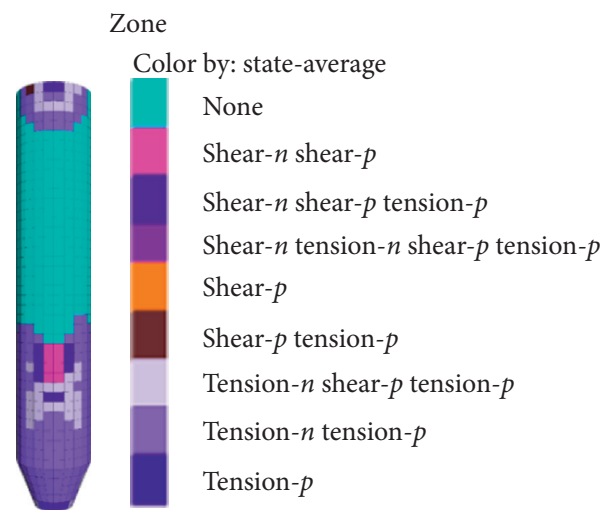

(e)

Figure 9: Distribution of plastic zone on the silo wall. (a) $\lambda=0.6$. (b) $\lambda=0.8$. (c) $\lambda=1.0$. (d) $\lambda=1.2$. (e) $\lambda=1.4$.

proportion of plastic zone in each state is $26.9 \%, 33.2 \%$, $34.3 \%, 47.4 \%$, and $49.6 \%$, respectively.

\subsection{Mechanism Analysis on the Fracture of the Silo Wall.} Due to the repeated loading and unloading of coal flow in the silo as well as the limitation of the outer surrounding rock, the silo wall is working under different lateral pressure. Thus, deformation at the original concrete defect position caused by the internal stress of the silo wall is first generated and further develops into fractures, which finally lead to macrodamage.

Since the construction of the lower lock of the shaft coal pocket and the loading chamber is an integrated whole, the intensity of the lower part is far stronger than that of the other areas. However, the upper mouth of the bunker which contacts the surrounding rock is only supported by a simple concrete arching structure without special treatment, which results in the silo wall mechanical structure with consolidation in the lower part and hinged constraint in the upper part. Therefore, the silo wall fracture shows asymmetry in the vertical deformation, for which the main reason is that the constraint of the silo wall in the surrounding rock is asymmetric. The lateral pressure coefficient plays an important role in the deformation and fracture of the silo wall, which is most prominent in the middle and lower areas of the silo wall.

6.5. Spot Effects. The research results have been successfully applied in Ganhe Coal Mine, Huozhou Mining Area, Shanxi Province. According to the on-site monitoring status, the roof-off-the-strata indicator set at the bottom of the shaft coal pocket kept monitoring within six months (from July 2016 to December 2016) and no obvious deformation occurred. Meanwhile, the cumulative displacement was less than $10 \mathrm{~mm}$ according to the observation. Now after 5 years (from 2016 to 2020) of safe and stable operation, the silo wall at the shaft coal pocket is still solid and intact, and no much damage occurred during the period. Up to now, the safeservice time of the repaired shaft wall has exceeded the previous maximum damage interval since the mine was put into production, with no record of repair. The restoration project has been proven to be a complete success with good effects.

\section{Conclusions}

The newly established mechanical model and numerical simulation experiments have revealed the feature of stability characterized by the wall of shaft coal pocket under different lateral pressure coefficients. The coal unloading process of the shaft coal pocket will lead to the changes of the stress and displacement of the shaft wall. Moreover, the lateral pressure coefficients have significantly different effects in controlling the stability of the shaft wall.

(1) The numerical simulation experiments have revealed that the middle and lower areas of the silo wall are the tensile stress concentrated region and the displacement reaches its maximum value, which is more conducive to the destruction of the silo wall in which tension plays a key role. The on-site observation is also consistent with this phenomenon, so this region on the shaft wall should be provided with key support and maintenance. Under different lateral pressure coefficients, the plastic zones preferentially expand in the middle and lower areas of the silo wall vertically.

(2) The radial displacement of the silo wall gradually expands with the increase of lateral pressure coefficients. The growth rate of the radial displacement basically decreases first and then increases. In addition, the radial displacement of the shaft wall follows the distribution of quadratic polynomial function and its $R^{2}$ value is 0.9562 .

(3) The silo wall overall presents the mechanical structure with consolidation in the lower part and hinged constraint in the upper part. Since the silo wall fractures exhibit constraint asymmetry in vertical deformation, the lateral pressure of different sides plays an important role in the silo wall deformation and fracture. Fractures occur in the middle and lower areas before they get damaged and turn unstable and then expand. Finally, the upper 
rock layers are damaged and tumble down from bottom to top by layers.

\section{Data Availability}

The data used to support the findings of this study are included within the article.

\section{Conflicts of Interest}

The authors declare that they have no conflicts of interest.

\section{Acknowledgments}

The authors would like to acknowledge the financial support from the National Natural Science Foundation of China (Grant nos. 51634007 and 51974226).

\section{References}

[1] N. J. Ma, Z. Li, and Z. Zhao, "Distribution of the deviatoric stress field and plastic zone in circular roadway surrounding rock," Journal of China University of Mining and Technology, vol. 44, no. 2, pp. 206-213, 2015.

[2] W. Zhu, X. Li, Y. Gao, and A. Sun, "Systematical study on stability of large underground houses," Chinese Journal of Rock Mechanics and Engineering, vol. 23, no. 10, pp. 16891693, 2004.

[3] X. R. Jia, Rock Mechanics and Strata Control, University of Mining and Technoleogy Press, Xuzhou, China, 2010.

[4] Z. L. Xu, A Concise Course in Elasticity, People's Education Press, Beijing, China, 1980.

[5] B. Y. Xu, "Concise clasticity and plasticity," Higher Education Press, Beijing, China, 2011.

[6] GB50077-2017, Standard for Design of Steel Reinforced Concrete Silos, National Standard of the People's Republic of China, Beijing, China, 2017.

[7] L. X. Fan and S. S. Zheng, "Finite element analysis of huge silo," Journal of Xi'an Mining Institute, vol. 16, no. 4, pp. 32-35, 1996.

[8] L. F. Yuan, "The finite element analysis and study on design method of the prestressed concrete circular silo," Master's thesis, Xi'an University of Architecture and Technology, Xi'an, China, 2011.

[9] M. Y. Liu and Y. P. Wu, "Repair design and engineering practice of shaft coal bunker," Coal Engineering, vol. 49, no. 7, pp. 14-17, 2017.

[10] C. B. Chen, Research on distribution of lateral bulk-solid pressures onsilo's wall, Ph.D. thesis, Hefei University of Technology, Hefei, China, 2006.

[11] Y. Wang and W. H. Yang, "Model of internal pressure on shaft wall," Journal of China Coal Society, vol. 40, no. 9, pp. 2049-2056, 2015.

[12] J. Xiong, P. Meng, and Z. Zhou, "Analysis in wall stress of large-diameter prestressed concrete coal silo under internal pressure," Journal of China Coal Society, vol. 35, no. 2, pp. 222-226, 2010.

[13] Q. L. Shao, H. T. Zhang, and Z. H. Liu, "The study of the technique of moving coal off-loading of vertical bunker," Journal of China Coal Society, vol. 23, no. 5, pp. 71-75, 1998.

[14] W. T. Li, S. C. Li, Q. Wang et al., "Full scale tests on U-steel confined concrete supporting arches under loads with different lateral pressure coefficients," Journal of China Coal Society, vol. 40, no. 9, pp. 2075-2084, 2015.

[15] S. Sun, J. Zhao, and C. Zhang, "Calculation of silo wall pressure considering the intermediate stress effect," Advances in Civil Engineering, vol. 2018, Article ID 3673515, 10 pages, 2018.

[16] R. Tatko and S. Kobielak, "Horizontal bulk material pressure in silo subjected to impulsive load," Shock and Vibration, vol. 15, pp. 543-550, Article ID 289317, 2008.

[17] D.-Z. Kong, Z.-B. Cheng, and S.-S. Zheng, "Study on the failure mechanism and stability control measures in a largecutting-height coal mining face with a deep-buried seam," Bulletin of Engineering Geology and the Environment, vol. 78, no. 8, pp. 6143-6157, 2019.

[18] X. K. Wang, W. B. Xie, J. B. Bai, S. Jing, and Z. Su, "Largedeformation failure mechanism of coal-feeder chamber and construction of wall-mounted coal bunker in underground coal mine with soft, swelling floor rocks," Advances in Civil Engineering, vol. 2019, Article ID 6519189, 16 pages, 2019.

[19] H. Yan, J. Zhang, N. Zhou, S. Zhang, and X. Dong, "Shaft failure characteristics and the control effects of backfill body compression ratio at ultra-contiguous coal seams mining," Environmental Earth Sciences, vol. 77, pp. 458-512, 2018.

[20] F. Gao, Research on ground stress distribution charcteristics and its effect on roadway surrounding rock stability, Ph.D. thesis, China University of Mining and Technology, Xuzhou, China, 2009.

[21] GB 50010-2010, Standard Concrete Structure Design Code, National Standard of the People's Republic of China, Beijing, China, 2015. 